\title{
6. THE INTERDISCIPLINARY DIMENSION OF THE VOCAL- CHORAL CULTURE OF THE PUPIL IN THE MUSIC SCHOOL
}

\author{
Ana Glebov ${ }^{51}$
}

\begin{abstract}
Process in the context of the vocal-choral culture of the students of the music school. The concept of interdisciplinary is considered as a symbiosis of two or more academic disciplines in the formation of the vocal-choral culture of pupils in the musical-artistic field. In this case, interdisciplinary occurs in integrating the knowledge, capabilities and aptitudes formed, taking into account significant specific factors. Thus, the interdisciplinary approach is carried out through such disciplines as solfeggio, history of music, instrument, ensemble, but also the integration into the vocal-choral of the method of interiorizing the music through the philosophical, musical and psycho-pedagogical aspects.
\end{abstract}

Key words: interdisciplinary, vocal-carnal culture, process, music interiorization

\section{Introduction}

The interdisciplinary approaches are in line with the current problems of modern education. The orientation to the integral perception of the world by students objectively reflects the requirements of the present times. The change of social relationships, the development of informational technologies, the multifunctionality of labor - all these impose on the modern student the multifaceted demands, which are focused on the multifunctionality of his knowledge, skills, methods of mental actions, the ability to apply and improve them in new life situations.

The modern concept of education aims to reflect the realities of life in teaching practice. The socio-humanitarian orientation of education, its "activity" side, is focused on the formation of common skills and abilities, the general methods of educational, cognitive, communicative, practical and creative activities. The practical orientation of education, its relevance to the results in life, the balance of fundamental and applied knowledge determines the use of interdisciplinary approaches in the elaboration of education content. As it is underlined in the modern concept of education, one of the aspects of updating the content of education, its integrity is the use of interdisciplinary links.

\section{Discussions}

The problem of interdisciplinarity finds various aspects of consideration in scientific and methodical works of various authors. The scientists associate these aspects with the concepts of "complexity", "integration", "interaction", "intersubject connections", and "synthesis". The thinkers of antiquity (Aurelius, Aristotle, Democritus, Pythagoras, Platon, etc.) reflected in the works the unity of the world and the interconnection of its multi-component processes, the interaction of the individuum and the world around him. The interdisciplinary

\footnotetext{
${ }^{51}$ Lecturer, Doctoral Candidate, „Alecu Russo” State University from Bălţi, Republic of Moldavia, email: annagl1982@mail.ru
} 
approaches have acquired a significant role in the philosophical works of $F$. Bacon, R. Descartes, I. Kant, and also in works on aesthetics of M. Kagan, D. Likhachev, A. Losev, B. Soloviev.

The idea of interdisciplinarity is widely used in research focused on human psychophysiology, that reflects the interdependence of the psychic and practical activities of the individuum, the phenomenon of associativeness of human thought (B. Ananiev, N. Berkhin, I. Pavlov, I. Sechenov, Y. Samarin). The research of these scientists convincingly proves that human activity, aimed at the cognition and transformation of the subject is the basis for the formation of logical connections and the relations of his consciousness.A complex mechanism of consciousness participates in the formation of an integral picture of the world. The art also contributes to the creation of "a whole sphere of artistic mastering of the world by the man" [6]. B. Asafyeva, L. Vygotsky, B. Medushevsky, B. Teplova describe in their works the connection between art and psycho-emotional sphere of man.

The interdisciplinary basis of various types of art forms an objective relationship, which is conditioned by their universal aesthetic nature. P. Florensky noted that "Despite the fundamental differences, the arts seem to grow from one and the same root, and it is worth starting to peer at them, it is more and more convincing as a unity" [9, p.63]. Aspects that touch the moments of the community of art were reflected to various degrees in educational programs, textbooks, teaching and methodological complexes of the aesthetic cycle subjects (D. Kabalevsky, V. Aleev, Y. Aliev, G. Danilova, B. Kuzin, T. Naumenko, B. Nemensky, L. Predtechenskaya, L. Rapacka, L. Shkolyar, T. Shpikalova, B. Yusov).

The research of the representatives of general pedagogy (G. Baturin, I. Zverev, V. Kirillov, Y. Komensky, I. Lerner, N. Loshkarev, K. Ushinsky, G. Fedorets, and others) is devoted to the aspects of interdisciplinary interactions. Let us define the concept of this term and different points of view on "interdisciplinarity". The Webster's dictionary*** gives the following definition: "interdisciplinarity includes two or more academic, scientific or artistic disciplines." In the dictionary "Wardnet" of Princeton University, interdisciplinarity - is the cooperation of two or more subject areas***. Interdisciplinarity is also defined as: combining two or more academic disciplines or developed subject areas or combining two or more professions, technologies, etc.*** We will adhere to the latter definition, that is, to understand interdisciplinarity as the union of two or more academic disciplines of vocal-choral culture.

A comprehensive study of the problem of interdisciplinary relations is of extreme importance both for the development of the scientific and theoretical foundations of pedagogy and for the practical activities of teachers. Namely the interdisciplinary ties are called upon to provide a single methodological basis for the subject system as a whole, based on the allocation of such systematizing scientific ideas that must permeate learning in all subjects. The process of learning in a whole is inseparably linked with this pedagogical category of 
"interdisciplinary connections". The interpretation of this concept in the literature is ambiguous. In the "Pedagogical Dictionary" it is defined as the mutual coherence of educational programs in various subjects.

R. Fedorets defines interdisciplinary connections as a pedagogical category "for designating synthesizing integrative relations between objects, phenomena and processes of reality, which found their reflection in the content, forms and methods of the educational process and performing educational, developmental and educational functions in their organic unity" [2, p.88] Interdisciplinary links are not only a mean of achieving general social goals of education - multilateral development of the student, but also one of the necessary factors for the formation of specific pedagogical tasks, the definition of general subject systems of knowledge, skills, references. Y. Babansky, focusing the attention on improving of the methodological foundations for the comprehensive development of the individuality in the process of education, underlines: "In the process of formation of general scientific skills and development of the will, emotions and abilities ... it is important to anticipate the formation of systemforming concepts, laws and theories, as well as the assimilation of fundamental scientific facts. It is possible to isolate them only by relying on the methodology for identifying the important, essential elements of the content.... " [1, p.26].

Interdisciplinary connections in a logically completed form represent a unified form, a conscious reference between the elements of the structure of various academic subjects. In classical pedagogy, the idea of interdisciplinary connections was born as a result in the search for ways to reflect the integrity of nature in the content of educational material. Y. Kamensky believed everything that is in a mutual connection, should be taught in the same way. He understood how important it is to establish a system of knowledge between subjects to form it in students and ensure the integrity of the learning process.

I. Pestalozzi revealed the diversity of the interconnections of school subjects. He proceeded from the requirement: "Bring into your mind all the essentially interconnected objects into the very connection in which they are in nature" [8, p.8]. K. Ushinsky gave the most complete psychological and pedagogical justification for the didactic significance of interdisciplinary connections. In the book "Man as an object of education," he derives them from associative links that reflect the objective interconnections of objects and phenomena. In his theory, the idea of interdisciplinary relations is as a part of a more general problem of the systemic nature of learning. Thus, in the history of pedagogy a valuable legacy has been accumulated on the theory and practice of interdisciplinary connections, and namely:

- has been formed (in terms of psychology, pedagogy and teaching methods) the objective necessity to reflect in the learning cognition the real interconnections between objects and phenomena of nature and society;

- the ideological and developing functions of interdisciplinary relations have been singled out; their positive influence on the formation of a true system of scientific knowledge and the general mental development of the student; 
- has been developed a methodology for coordinated teaching of various subjects, have been made attempts to prepare the teacher for interdisciplinary connections in practice.

From the standpoint of philosophical analysis, interdisciplinary connections act as a didactic form of the universal principle of systemic nature. In the didactic theory of interdisciplinary connections, the teachers identified three main groups:

1) by types of knowledge - informative-informational (scientific);

2) by types of skills - operational-active, identifiable, practical, value-oriented;

3) the method of implementation in the educational process - organizational and methodological.

The degree of implementation of interdisciplinary links can be different. It depends on the content of the lesson. At the most primitive level, the principle of using interdisciplinary links is expressed in a general complex approach to the formulation and solution of teaching and educational tasks. The next level is fragmentary level. Here, interdisciplinary connections are carried out in the construction of educational material in the form of elements, examples, general facts, concepts and constitute a fragment in the structure of the lesson. The higher level implies the organic inclusion of the educational material from other subjects into the structure of the lesson, without which the new material of the program, which requires generalization, synthesis of knowledge, cannot be well studied. At the highest, synthesized level, repeated-generalizing lessons are organized, where knowledge from various subjects is united from the position of common ideological ideas. In primary school are the most acceptable and most often used in pedagogy are interdisciplinary connections based on the three levels mentioned earlier.

In pedagogical practice the distinction of interdisciplinary connections fulfills educational, schooling and developmental functions.

The educational function includes:

1) The improvement of the content of training - one of the criteria of selection and coordination of educational material in related disciplines planning;

2) The formation of a systematic knowledge about the world on the basis of the development of leading scientific ideas and scientific concepts;

3) The formation of polytechnic knowledge and skills.

The educational function of interdisciplinary relations includes:

1) The formation of the world outlook;

2) The labor education;

3) The professional orientation.

Developing function implies the development of systemic thinking, cognitive interests and cognitive activity. The formation of moral and aesthetic ideals of students is one of the most important functions of interdisciplinary relations in school education. Interdisciplinarity connection is the most important factor in the learning process optimization, increase of its effectiveness, and elimination of the overload for teachers and students. A particular importance get interdisciplinary connections and serve for the 
effective use of organizational forms of education, as well as targeted restructuration of all the main units during the educational process:

-integrated formulations of the lesson's tasks, including general, related concepts;

-organization of cognitive activity of students;

-complex use of means of educational activity activation, typical visual aids for subjects which the connection is established;

-analysis of levels of training and development;

-integrated lesson by lesson and thematic planning.

The restructuration of all the units of educational process of interdisciplinary connections is aimed to form an active position of the student during the learning process. This process provides a common implementation of the educational, developmental and educational functions; the unity of science and philosophy instruction contents and active educational and cognitive activities of students. So, the accessibility of learning on the basis of interdisciplinary connections is ensured by the training process organization itself. It does not only include general interdisciplinary elements in the content of educational and cognitive activities, but also contributes to the formation of a general ability for students to use them.

\section{Results}

Taking into account all the conclusions and following the logic of the present article, let us turn to the identification of the problem, and namely to the interdisciplinarity of the process of the vocal-choral culture formation. Let us consider the totality of subjects which are in interdisciplinary connection with the vocal and choral activities at music school. The main subject at music school is a specialty - it is an individual lesson of playing an instrument (piano, violin, flute, etc.), because the subject of specialty is based on artistic knowledge and creative activity. We consider functions of interdisciplinarity first of all as a development function:

1) The development of musical abilities;

2) The improving the creative potential;

3) The formation of emotional perception;

4) The development of musical thinking.

The educational function includes:

1) The improvement of the musical training content - one of the criteria for selection and coordination of educational material in programs of related disciplines: solfeggio, musical literature.

2) The formation of a systematic knowledge of music and musical knowledge (musical subjects in the school);

3) The formation of interdisciplinary musical knowledge and skills.

The educational function of interdisciplinary connections includes:

1) The formation of a worldview;

2) The spiritual upbringing;

3) The professional orientation. 
Development function implies the development of musical thinking, musical-cognitive interests and musical-cognitive activities. The most important function of interdisciplinary relations at music school is the formation of the spiritual and aesthetic ideals of students. In a special equipped classroom, the students receive most of the practical skills - handle of the instrument, technical equipment, confident reading of notes, which presents an extreme necessity in the vocal-choral class. Solfeggio is the following most important subject of the entire training cycle. Solfeggio - activity aimed on the purposefulness and multilateral development of musical hearing through vocal-choral singing, conducting, playing and listening. Solfeggio is an extremely useful and effective subject that helps many children in musical development. Within this discipline, children also receive most of the information about musical theory.

History of music a subject that is included in high school timetable and is studied by pupils for four years at music school. The subject broadens the horizons of students and their knowledge of music, art and vocal and choral art in general. The students learn the biographies of composers and their main creations and masterpieces (they are listened and studied in details in the classroom). For four years students have plenty of time to get acquainted with the main problems of the subject, to study many styles, genres and forms of music. Here we draw the conclusions that the interdisciplinarity of the process unites and connects all subjects together, at the same time influences the formation of the vocal-choral culture. As a result, they receive not only musical, but also a colossal vocal-choral experience. They are at a fairly high level playing one of the musical instruments, they can play one or two other instruments, they intonate. In addition, at music school, children receive:

- an enormous intellectual base;

- become more erudite;

- develop mathematical abilities.

Inseparable connection with the spiritual culture is one of the characteristic interdisciplinary aspects in the formation of the vocal-choral culture. In this context, there are many methodological works, which in their great part, point to the formation of vocal-choral culture. However, very few ways of formation of a spiritual culture have been explored. In the modern concept of musical perception, the researcher I. Gagim, paid more attention to this problem and developed certain ways for its realization. A special interest in this methodology came from the method of interiorization, which means" the translation of music from the outer world into the inner, its transformation from sound-physical substance (energy) into spiritual. This method means - the internalization of music ( its identification), all our inner consciousness receives a state of music, that is not an ordinary, but a transformed state (with a positive sign in the case of real music and with a negative sign in case of anti-destructive music)" [3, p. 146]. The psychological concept of state of music, formulated by I. Gagim, resonates with the psycho-musicological concept of the mode-state by E. Nazaikinsky [7, p.236]. 


\section{Conclusions}

The method of interiorization of music the scientist suggests to realize by means of such methods as: thoughtful singing; plastic intonation with simultaneous mental tracking of the sound line (vox mentis - mental voice); "meditative" hearing; singing a melody in a low voice, with a gradual transition to "silent" singing. Thus, "Music, lies down to the depth / on the basis of "I," becomes an internal living energy, which, sounded by numerous living melodies at the depth of consciousness, fills the senses, directs thoughts, actions, actions" [4, p.146].

Thus, we accept the fact that I. Gagim considers the method of interiorization as an interdisciplinary aspect, and as one of the most important means of spiritual enrichment. So, at music school, the primary goal of the formation of the vocal-choral culture of pupils is the spiritual culture, which is concretized, has a spiritual and moral character and can develop according to the interdisciplinary principle, by the method of interiorization.

\section{Bibliography}

1. Babansky Yu., (1988), Ed. Pedagogy. Moscow.

2. Fedorets R., (1983), Interdisciplinary connections in the learning process. Ed. Leningrad.

3. Gagim, I., (1996), Ştiinţa şi arta educaţiei muzicale. Ed. ARC, Chişinău.

4. Gagim, I., (2003), Dimensiunea psihologică a muzicii, Ed. Timpul, Iaşi.

5. Gagim, I., (2004), Music as a great pedagogy. Musical and pedagogical education at the turn of the 20th and 21st centuries. Materials of the VIII International Conference. Ed. Moscow.

6. Kagan M., (1987), Music in the Art World. / Soviet Music No. 1. Ed. Moscow.

7. Nazaikinsky E., (1982), Logic of the musical composition. Ed. Education. Moscow.

8. Pestalozzi I., (1985), Izbr. ped. op. - ed. Moscow.

9. Schelling F., (1966), The Philosophy of Art. Ed. Moscow.

\section{Online resources:}

1.***Materials of the site http://www.merriam-webster.com/info/copyright.htm;

2. *** Materials of the site (2006), Word Net ${ }^{\circledR}$ 3.0, by Princeton University; 3.***Materials of the site (2006), Dictionary.com Unabridged ( $\mathrm{v}$ 1.1), (C) Random House, Inc. 